\title{
MODIFIKASI ALAT MEDIS STETOSKOP UNTUK MONITORING SUARA JANTUNG MENGGUNAKAN TAMPILAN GUI MATLAB
}

\author{
Dessy Irmawati ${ }^{1} \&$ Ridho Prasakti ${ }^{2}$ \\ ${ }^{1,2}$ Universitas Negeri Yogyakarta \\ E-mail: dessy.irmawati@uny.ac.id
}

\begin{abstract}
Heart sounds are very important for the initial diagnosis of a disease. This article aims to modify the stethoscope's medical device by adding a Low Pass Filter (LPF) and a condenser sensor so that data can be recorded in a digital device. The stages of tool development begin with analysis, design, development and testing. At the analysis stage, it was stated that a conventional medical stethoscope can only be done by a medical expert directly, where data cannot be stored for detailed analysis purposes, the device is not equipped with LPF which can limit the frequency in a certain range, monitoring data can displayed in the Matlab GUI. The results of testing tools through functional tests indicate that the addition of LPF can reduce noise when retrieving heart sound data and data can be monitored through the Matlab GUI display. The results of the development of this tool are expected to improve accuracy in diagnosing heart sound abnormalities through monitoring data on the Matlab GUI display. The mean frequency of heart sounds obtained from the device testing data is in the range of $20-400 \mathrm{~Hz}$.
\end{abstract}

Keywords: stethoscope modification, heart sound, Matlab GUI

\section{ABSTRAK}

Suara jantung merupakan hal yang sangat penting untuk diagnosis awal suatu penyakit. Artikel ini bertujuan untuk memodifikasi alat medis stetoskop dengan menambahkan suatu Low Pass Filter (LPF) serta sensor kondensator agar data dapat direkam dalam suatu perangkat digital. Tahapan pengembangan alat diawali dari analisis, perancangan, pengembangan, serta pengujian. Pada tahapan analisis, dinyatakan bahwa alat medis stetoskop konvensional hanya dapat dilakukan oleh seorang ahli medis secara langsung, dimana data tidak dapat disimpan untuk keperluan analisa yang lebih detail, pada alat tersebut belum dilengkapi dengan LPF yang dapat membatasi frekuensi pada rentang tertentu, monitoring data dapat ditampilkan dalam GUI Matlab. Hasil pengujian alat melalui uji fungsional menunjukkan bahwa penambahan LPF dapat mengurangi derau saat mengambilan data suara jantung serta data dapat dimonitor melalui tampilan GUI Matlab. Hasil pengembangan alat ini diharapkan dapat meningkatkan akurasi dalam mendiagnosis kelainan suara jantung melalui monitoring data pada tampilan GUI Matlab. Rerata frekuensi suara jantung yang diperoleh dari data pengujian alat yaitu pada rentang $20-400 \mathrm{~Hz}$.

Kata kunci: modifikasi stetoskop, suara jantung, GUI Matlab

\section{PENDAHULUAN}

Survei Sample Registration System (SRS) pada tahun 2014 di Indonesia, menunjukkan Penyakit Jantung Koroner (PJK) menjadi penyebab kematian tertinggi pada semua umur setelah stroke, yakni $12,9 \%^{(1)}$. Kondisi tersebut dapat terjadi disebabkan kurangnya kepedulian masyarakat terhadap kesehatan, misalnya masih adanya perokok (pasif/aktif), kurangnya aktifitas fisik, diet yang tidak seimbang, istirahat yang kurang, tidak dilakukanya pemeriksaan kesehatan secara berkala, serta stress yang tidak terkendali. Menurut Kemenkes RI, 2017 PJK paling banyak terjadi pada kelompok usia 6574 tahun $(3,6 \%)$, usia 75 tahun ke atas $(3,2 \%)$, usia 55-64 tahun $(2,1 \%)$, dan kelompok usia 35-44 tahun (1,3\%). Sejalan dengan hal tersebut, menurut Utami \& Fajar $^{(2)}$ menyatakan bahwa deteksi dini penyakit jantung dapat dikalukan dengan melakukan pengecekkan frekuensi denyut jantung secara teratur.

Analisa suara jantung diperlukan untuk mengetahui kelainan pada fungsi jantung ${ }^{(3)}$. Beberapa cara pemeriksaan fisis jantung 
anatar lain: (1) inspeksi; (2) Palpasi; (3) Perkusi; dan (4) Auskultasi ${ }^{(4)}$. Auskultasi jantung merupakan cara paling sering dimanfaatkan sebagai proses menginvestigasi informasi penting terkait kesehatan jantung ${ }^{(5)}$. Stetoskop digunakan sebagai alat bantu medis untuk pemeriksaan dengan cara auskultasi, dimana dokter mendengarkan suara jantung pasien. Keahlian dan keteliatian seorang dokter diperlukan untuk mendengarkan suara jantung dengan cara auskultasi, peletakan stetoskop menentukan hasil diagnosis seorang dokter. Apabila terjadi kesalahan dalam cara pengambilan suara jantung, maka dapat dimungkinkan akan tertangkap suara dari aktifitas organ tubuh yang lain. Suara jantung normal memiliki rentang frekuensi antara 20 $\mathrm{Hz}$ hingga $500 \mathrm{~Hz}$, sedangkan frekuensi suara paru normal $750 \mathrm{~Hz}$ dan yang kelainan parenkin antara $300 \mathrm{~Hz}$ sampai $340 \mathrm{~Hz}^{(6)}$. Berdasarkan rentang frekuensi tersebut, terlihat bahwa frekuensi suara paru berada pada rentang frekuensi suara jantung, hal ini dapat menyebabkan derau pada saat diagnosis suara jantung.

Penerapan filter dapat digunakan untuk mengatasi derau, Low Pass Filter (LPF) akan diterapkan pada pengembangan modifikasi stetoskop dengan bantuan tampilan GUI Matlab. Penerapan filter dan tampilan GUI ini dapat mempermudah diagnosis. Modifikasi stetoskop ini juga memudahkan dalam perekaman data, dengan menyimpan suara jantung dalam bentuk digital. Modifikasi stetoskop ini dikembangkan untuk memberikan kemudahan dalam melakukan rekam data suara jantung.

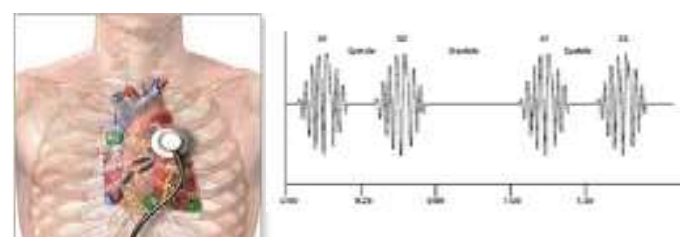

Suara jantung $(*$.wav $)$

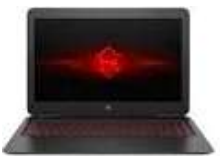

Komputer

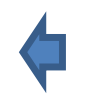

Penguat dan filter

\section{METODE}

Prosedur pengembangan tersaji pada Gambar 1. Prosedur pengembangan terdiri atas: (1) analisis kebutuhan untuk mengetahui kebutuhan-kebutuhan pengembangan; perancangan rangkaian penguat, LPF dan GUI Matlab; (3) pengembangan; dan (4) pengujian.

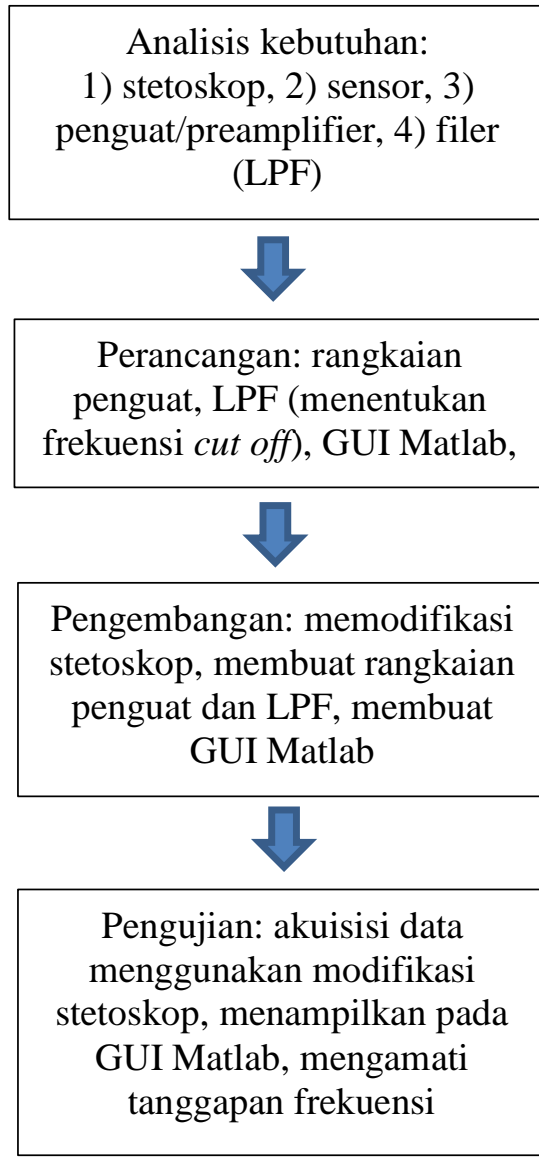

Gambar 1. Prosedur Pengembangan

Secara umum, suara jantung direkam dalam format *.wav menggunakan stetoskop yang telah dimodifikasi menggunakan sensor mic, penguat dan filter melalui komputer. Gambar 2 menampilkan diagram blok perancangan.

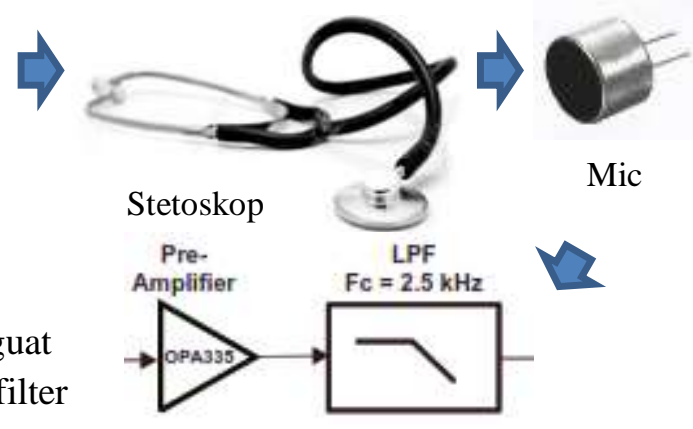

Gambar 2. Diagram Blok Perancangan 
GUI Matlab dibuat untuk merekam suara jantung dalam format *wav mono dan menampilkan suara jantung dalam domain waktu dan domain frekuensi, disajikan pada Gambar 3. GUI (Graphical User Interface) dibuat dengan software Matlab R2014. GUI tersebut dilengkapi dengan beberapa button untuk merekam suara jantung, menyimpan, menyuarakan, mengubah ke dalam domain frekuensi, menampilkan, dan membuka file. Data suara dalam domain waktu dan domain frekuensi ditampilkan untuk mengetahui spektrum frekuensi sinyal suara jantung.

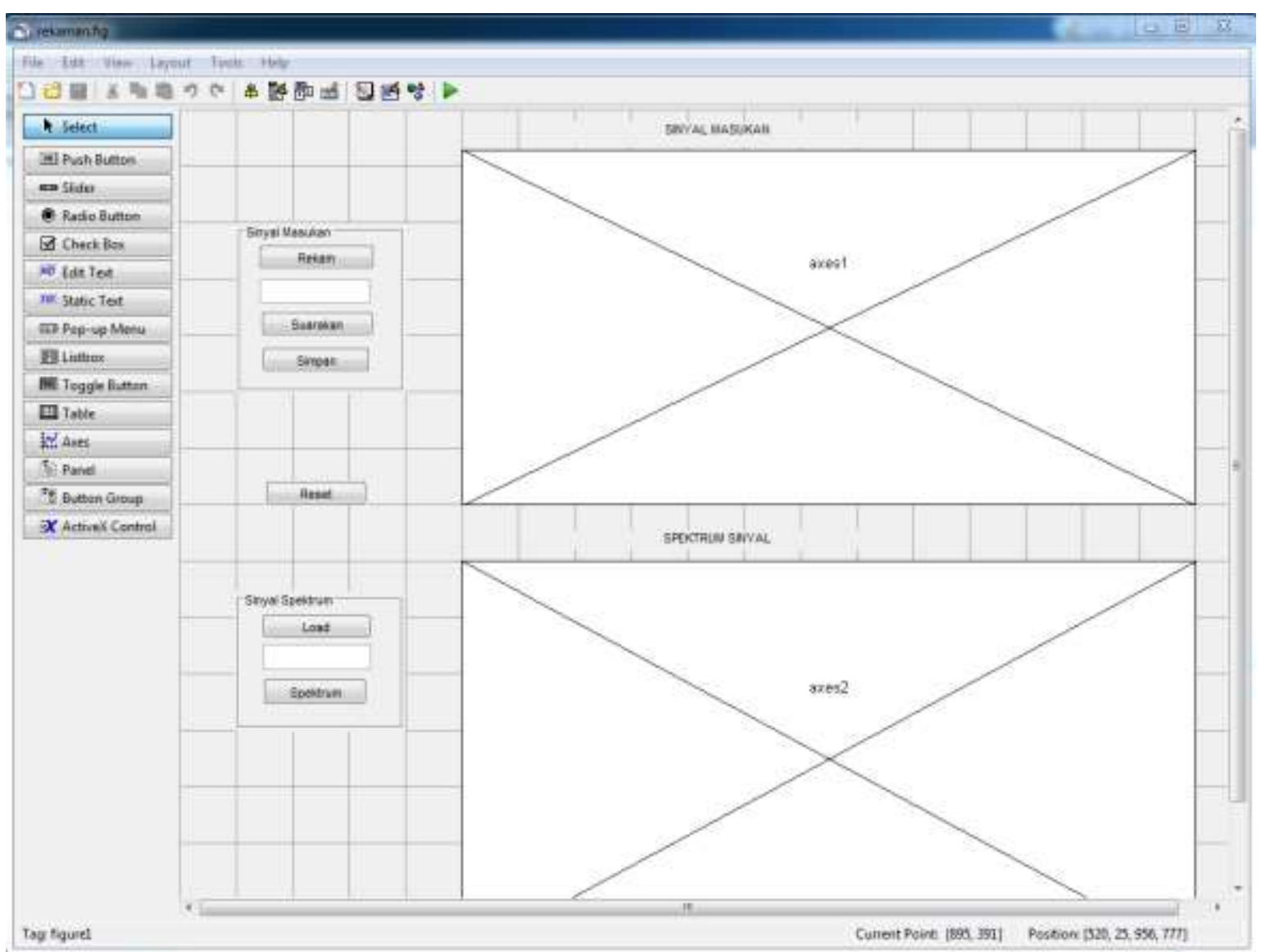

Gambar 3. Tampilan GUI Matlab

Prosedur terakhir adalah pengujian, dengan diawali akuisisi data dengan data sampel direkam menggunakan modifikasi stetoskop yang dihubungkan ke sebuah komputer, berjumlah 9 data suara jantung. Menampilkan data suara jantung melalui GUI Matlab, untuk melihat spektum frekuensi suara jantung dari hasil perancangan Low Pass Filter. Perhitungan sinyal suara jantung dalam domain frekuensi, menggunakan algoritma Fast Fourier Transform (FFT). FFT akan mengubah sinyal suara jantung dalam domain waktu ke domain frekuensi dengan persamaan berikut $^{(7)}$ :

$$
X(F)=\int_{-\infty}^{\infty} x(t) e^{-t 2 \pi F t} d t
$$

Sedangkan respon frekuensi dapat diketahui dari gambar diagram bode yang dibangkitkan melalui commad Matlab. Sintak Bode pada Matlab membuat gambar Bode dari tanggapan frekuensi dengan menampilkan frekuensi ( $\mathrm{rad} / \mathrm{s})$ dan magnitudo $(\mathrm{dB})$ dari respon sistem dalam fungsi frekuensi.

Peralatan yang digunakan untuk melihat frekuensi cut off filter dan penguatan adalah dengan memanfaatkan frekuensi generator 
sebagai masukan dan osiloskop untuk penampil, seperti pada Gambar 4.

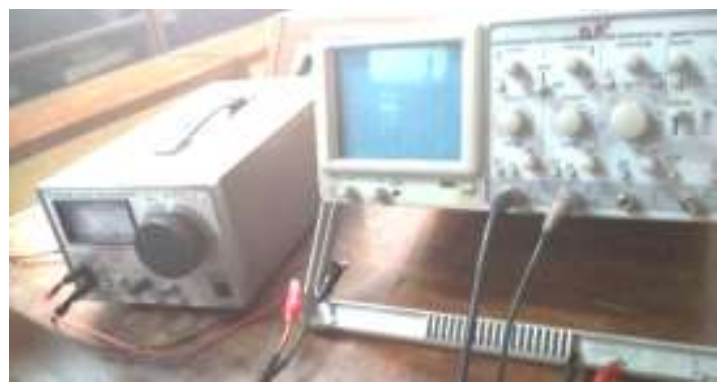

Gambar 4. Frekuensi Generator dan osiloskop.

\section{HASIL DAN PEMBAHASAN}

Pengaturan trimpot pada rangkaian Gambar 5 agar didapatkan hasil pemfilteran yang stabil. Tabel 1 menampilkan data pengujian filter, dengan memberikan masukan dari frekuensi generator mulai dari frekuensi $20 \mathrm{~Hz}$ hingga $10 \mathrm{KHz}$. Hasil pengujian pada tabel 1, terlihat bahwa kondisi jenuh terjadi pada saat masukan pada frekuensi $50 \mathrm{~Hz}$ hingga $1 \mathrm{KHz}$, kemudian frekuensi turun pada saat frekuensi $2 \mathrm{KHz}$. Berdasarkan pengujian tersebut, maka frekuensi cut off yang dihasilkan yaitu $2 \mathrm{KHz}$. Mengacu pada stetoskop digital dengan Frekuensi cut off sebesar 2,5 $\mathrm{KHz}^{[8]}$, maka modikasi stetoskop yang telah dikembangkan sudah memiliki frekuensi cut off yang mendekati stetoskop digital yang dikembangkan oleh Texas Instrumen, selanjutnya alat ini dapat dilakukan untuk mengambilan data suara jantung.

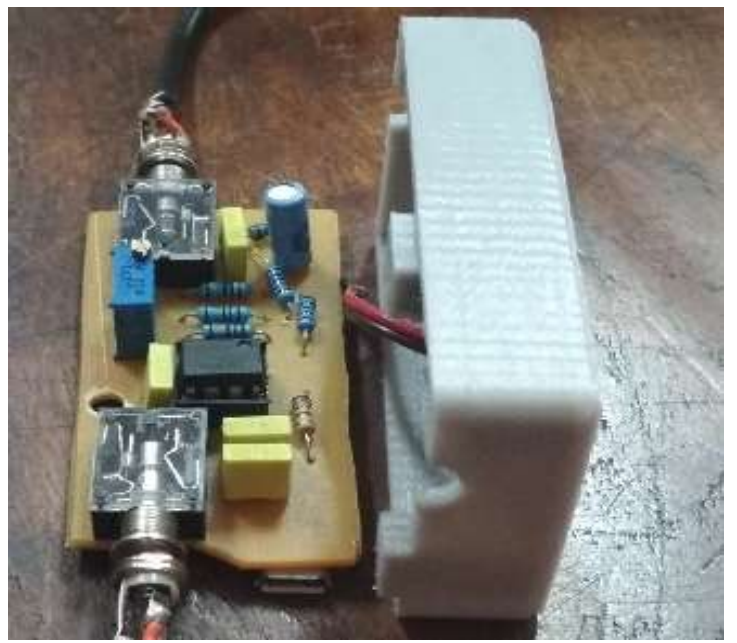

Gambar 5 Rangkaian Penguat dan filter
Tabel 1. Pengujuan Frekuensi Cut Off

\begin{tabular}{ccc}
\hline Frek $(\mathrm{Hz})$ & $\begin{array}{c}\text { Teg }(\mathrm{V}) \\
\text { Amplitudo }\end{array}$ & $\begin{array}{c}\text { Teg }(\mathrm{V}) \\
\text { Osiloskop }\end{array}$ \\
\hline 20 & 0,24 & 1,9 \\
30 & 0,24 & 1,9 \\
50 & 0,24 & 2 \\
100 & 0,24 & 2 \\
500 & 0,24 & 2 \\
$1 \mathrm{~K}$ & 0,24 & 2 \\
$2 \mathrm{~K}$ & 0,24 & 1,6 \\
$2,5 \mathrm{~K}$ & 0,24 & 1,1 \\
$5 \mathrm{~K}$ & 0,24 & 0,8 \\
$10 \mathrm{~K}$ & 0,24 & 0,45 \\
\hline
\end{tabular}

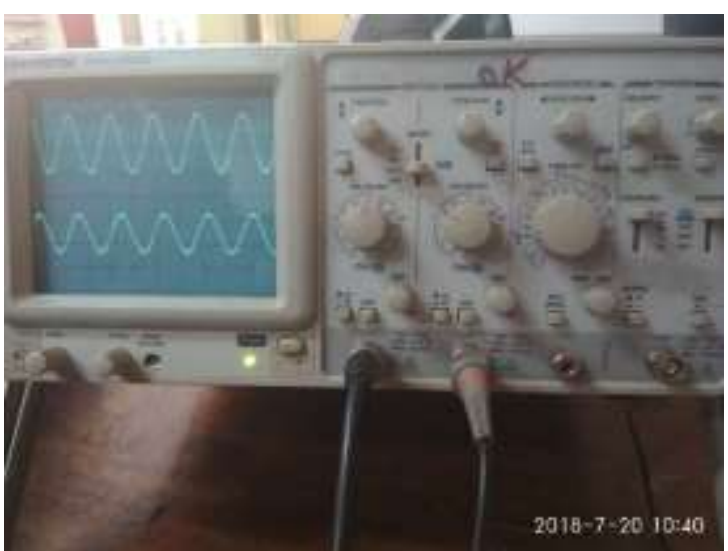

Gambar 6. Uji Penguatan

Pengujian penguatan dilakukan dengan memberikan masukan dari frekuensi generator, terlihat pada gambar 6, penguatan yang dihasilkan dari pengaturan Channel 1 dengan Volt/Div 0,1 Volt yang dihubungkan ke frekuensi generator (masukan), terhitung 0,1 Volt $\times 8=0,8$ Volt. Channel 2 dengan Volt/Div 0,5 Volt, dihubungkan ke rangkaian penguat, menghasilkan keluaran 0,5 Volt $\mathrm{x} 12$ $=6$ Volt. Hasil pernguatan dihitung dengan membandingkan tegangan keluaran terhadap tegangan masukan, dengan rumus sebagai berikut:

$$
\begin{aligned}
\text { Av } & =\text { Vin } / \text { Vout } \\
& =6 / 0,8 \\
& =7,5 \mathrm{kali}
\end{aligned}
$$

Penguatan yang dihasilkan dari rangkaian penguat gambar 5 adalah sebesar 7,5 kali.

Data masukan diambil data dari 3 sumber orang yang berbeda, sebagai hasil uji coba perekaman sinyal suara jantung, masingmasing 3 (tiga) kali perekaman. Tujuannya 
adalah untuk melihat variasi spektrum yang didapatkan dari sumber yang berbeda.

Perekaman suara jantung dilakukan dengan cara menghubungkan stetoskop ke port masukan rangkaian penguat dan filter gambar 5 , kemudian port keluaran dihubungkan ke port audio laptop. Perekaman suara menggunakan GUI Matlab berdurasi 5 detik dengan sistem mono, setelah 5 detik maka file dapat disimpan dalam format wav. File tersebut dapat dibuka kembali serta dapat disuarakan. GUI Matlab menampilkan dua gambar sinyal suara jantung, yaitu pada bagian atas dalam domain waktu dan pada bagian bawah dalam domain frekuensi (spektrum). Gambar 7 hingga 9 menampilkan 9 data suara jantung. Hasil perekaman didapatkan amplitude yang sangat kecil, dengan frekuensi pada rentang normal $20-400 \mathrm{~Hz}$.

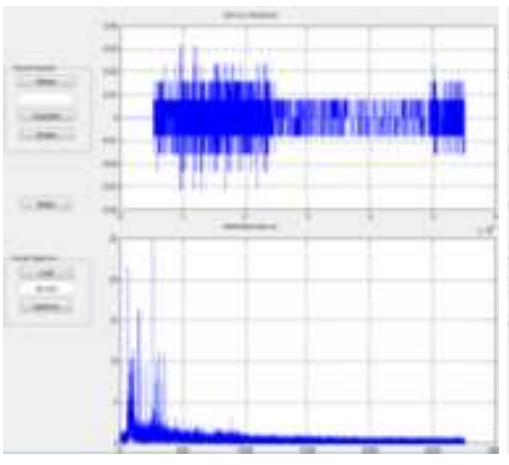

(a) "dsi.wav"

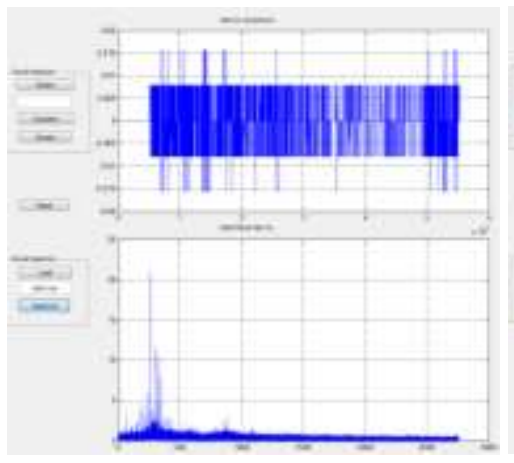

(b) "dsi2.wav"

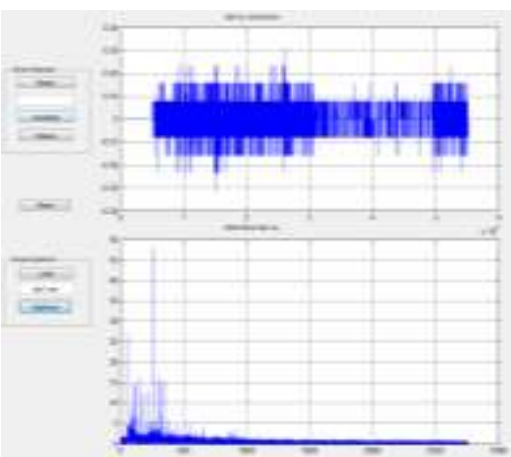

(c) "dsi3.wav"

Gambar 6. Tampilan Suara Jantung dsi
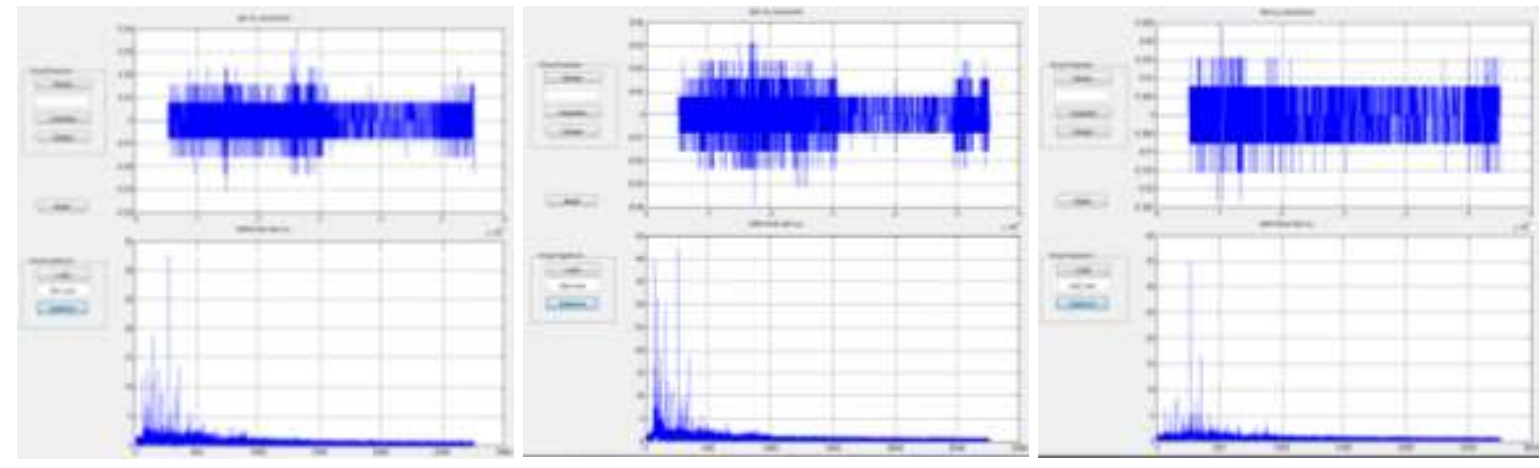

(a) "nta1.wav" (b) "nta2.wav" (c) "nta3.wav"

Gambar 7. Tampilan Suara Jantung nta
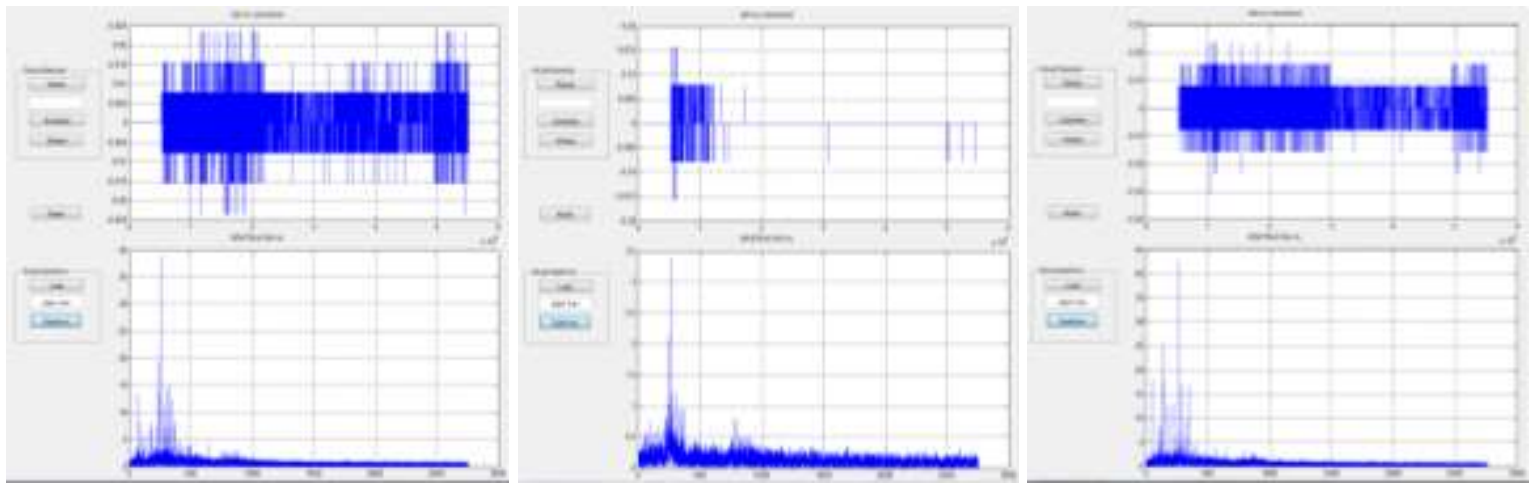

(a) "pap1.wav" (b) "pap2.wav" (c) "pap3.wav"

Gambar 8. Tampilan Suara Jantung pap 
Tabel 2. Frekuensi Suara Jantung

\begin{tabular}{cc}
\hline Nama & F $(\mathbf{H z})$ \\
\hline dsi.wav & $20-400$ \\
dsi2.wav & $40-400$ \\
dsi3.wav & $60-400$ \\
nta1.wav & $40-500$ \\
nta2.wav & $50-400$ \\
nta3.wav & $50-400$ \\
pap1.wav & $50-400$ \\
pap2.wav & $50-400$ \\
pap3.wav & $50-400$ \\
\hline
\end{tabular}

Tabel 2 menjelaskan nilai frekuensi sinyal suara jantung berdasarkan spektrum sinyal yang terlihat pada gambar 7 hingga 9 bahwa modifikasi stetoskop yang sudah dikembangkan dapat meloloskan frekuensi rendah dengan frekuensi cut off $(\mathrm{Fc}) 2 \mathrm{KHz}$, sehingga modifikasi stetoskop hanya dapat menangkap frekuensi di bawah $2 \mathrm{KHz}$. Hal ini sesuai dengan rentang frekuensi jantung yang berada pada frekuensi rendah 0-400 $\mathrm{Hz}$. Tampilan spektrum sinyal suara, yang mana pada sumbu horizontal merupakan nilai frekuensi dan sumbu vertikal merupakan nilai magnitude. Sinyal suara dengan magnitude tinggi, terlihat nilia frekuensi pada rentang rata-rata 20 hingga $400 \mathrm{~Hz}$. Rentang frekuensi yang terbaca diambil dari data suara jantung normal, sehingga hasil tersebut sudah sesuai dengan rentang frekuensi jantung normal yaitu $20-400 \mathrm{~Hz}$.

Gambar 10 hingga 12 merupakan gambar bode yang menunjukkan tanggapan frekuensi dari Low Pass Filter, terlihat bahwa semakin tinggi frekuensi sampai batas frekuenci cut off yang sudah ditetapkan, maka semakin kecil nilai magnitudonya, dan bahkan selalu turun hingga mendekati nilai nol.
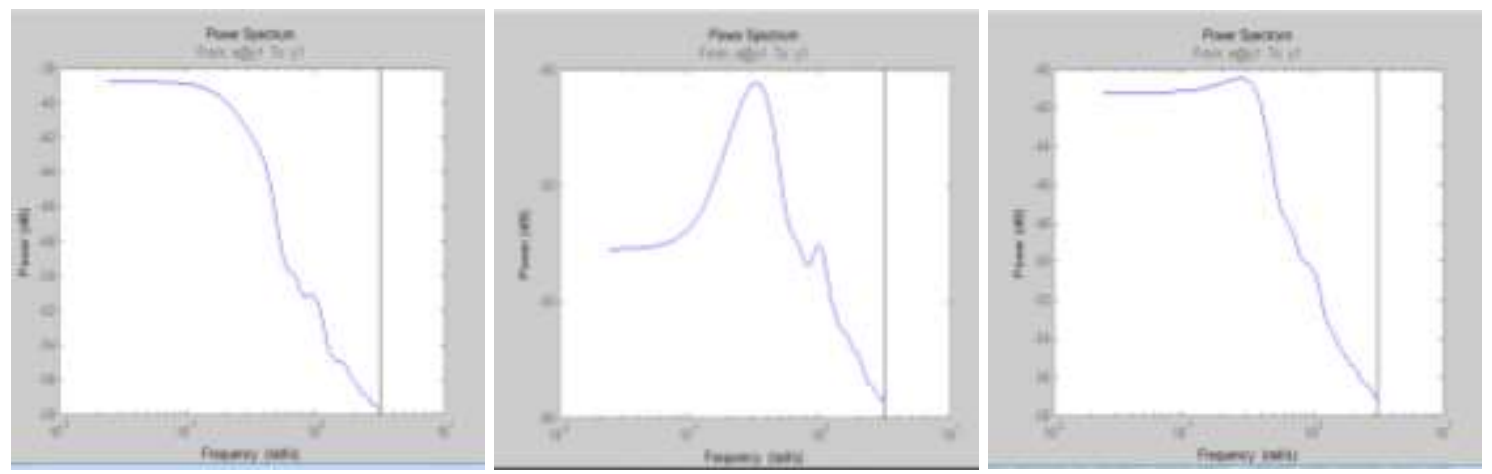

(a) Bode "dsi.wav" (b) Bode "dsi2.wav" (c) Bode "dsi3.wav

Gambar 10. Diagram Bode "dsi.wav","dsi2.wav","dsi3.wav"
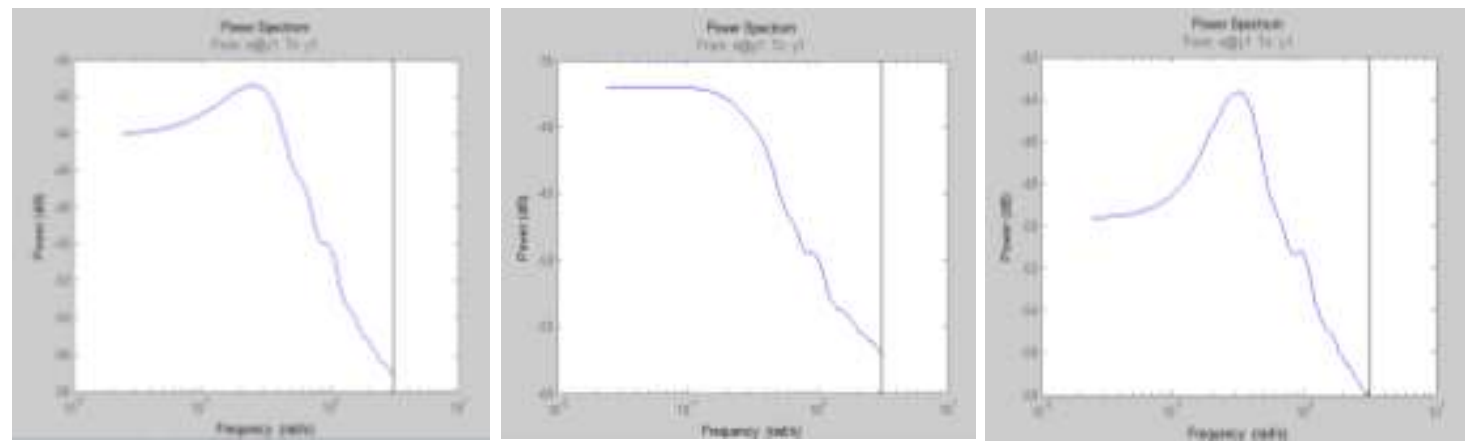

(a) Bode "nta1.wav" (b) "nta2.wav" (c) "nta3.wav

Gambar 11. Diagram Bode "nta1.wav","nta2.wav","nta3.wav" 

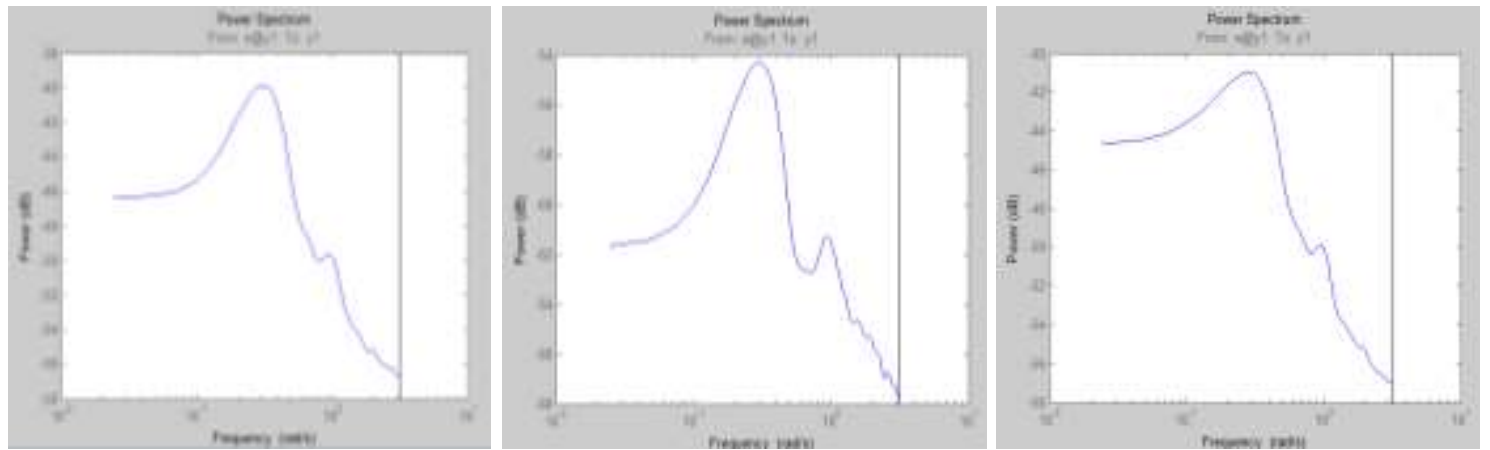

(a) "pap1.wav" (b) "pap2.wav" (c) Bode "pap3.wav"

Gambar 12. Diagram Bode "pap1.wav","pap2.wav","pap3.wav"

\section{SIMPULAN}

Stetoskop yang sudah dimodifikasi dengan menambahkan sensor mic di dalam membran stetokop, kemudian digunakan sebagai masukan untuk rangkaian penguat dan difilter menggunakan LPF. Hasil yang diperoleh, ditunukkan oleh tampilan GUI Matlab berupa sinyal suara jantung yang direkam dan dapat disimpan, serta spektrum frekuensi yang berada pada rentang frekuensi rendah, yaitu 0-400 Hz. Tanggapan frekuensi dijelaskan melalui grafik bode, yang menunjukkan hanya frekuensi rendah saja yang diloloskan, dengan $\mathrm{Fc}=2 \mathrm{KH}$, hal ini sudah sesuai dengan rancangan LPF.

\section{REFERENSI}

[1] Depkes, (2018,8,13), Penyakit Jantung Penyebab-Kematian, http://www.depkes.go.id/article/view/170 73100005/

[2] Utami P., \& Fajar, M. "Pengembangan Trainer Indikator Denyut Jantung". Elinvo, 1(1). 2015.
[3] Ira Puspasari,dkk, "Analisis Ekstraksi Ciri Pada Suara Jantung Diastolik dengan menggunakan Wavelet Transform dan Wigner Ville Distribution". NY

[4] NN. "Buku acuan Peserta CSL 2 Seri 3 Pemeriksaan Fisis Jantung". Fak. Kedokteran UNHAS. NY

[5] James N, et al. "Quantitative Analysis of Heart Sounds and Systolic Heart Murmurs Using Wavelet Transform and AR Modeling". IEEE. 2010

[6] Kemalasari, dkk, "Deteksi Kelainan Parenkim Paru Berdasarkan Power Spectra Density Suara Paru Dengan Metode Welch", EEPIS, 2011

[7] Proakis,Monolakis."Digital Signal Processing 4th Edition". Prentice Hall, NY

[8] NN. "Digital Sthetoscope Implementation on the TMS320C5515 DSP Medical Development Kit (MDK). Texas Instrumen, 2010 